\title{
Neuronal mechanisms and circuits underlying repetitive behaviors in mouse models of autism spectrum disorder
}

\author{
Hyopil Kim, Chae-Seok Lim* and Bong-Kiun Kaang*
}

\begin{abstract}
Autism spectrum disorder (ASD) refers to a broad spectrum of neurodevelopmental disorders characterized by three central behavioral symptoms: impaired social interaction, impaired social communication, and restricted and repetitive behaviors. However, the symptoms are heterogeneous among patients and a number of ASD mouse models have been generated containing mutations that mimic the mutations found in human patients with ASD. Each mouse model was found to display a unique set of repetitive behaviors. In this review, we summarize the repetitive behaviors of the ASD mouse models and variations found in their neural mechanisms including molecular and electrophysiological features. We also propose potential neuronal mechanisms underlying these repetitive behaviors, focusing on the role of the cortico-basal ganglia-thalamic circuits and brain regions associated with both social and repetitive behaviors. Further understanding of molecular and circuitry mechanisms of the repetitive behaviors associated with ASD is necessary to aid the development of effective treatments for these disorders.
\end{abstract}

Keywords: Autism spectrum disorder, ASD mouse models, Repetitive behaviors, Cortico-basal ganglia-thalamic circuits

\section{Background}

Autism spectrum disorder (ASD) is a neurodevelopmental disorder, and according to the 5th edition of the Diagnostic and Statistical Manual of Mental Disorders (DSM-5), it is characterized by "an impairment in social communication and interaction, and restricted and repetitive patterns of behaviors, interests or activities." A subset of patients with ASD tend to also display hyperactivity, anxiety, hypotonia, epilepsy, sensory abnormalities, sleep disorders, intellectual disabilities, gastrointestinal disorders, microencephaly or megalencephaly [1-4]. The symptom severity is also heterogeneous, which is why the term ASD is used to encompass all the different severities and variations of symptoms in these disorders.

ASD patients show a range of repetitive behaviors, including stereotypies, rituals, compulsions, obsessions and self-injurious. The repetitive behaviors of each

*Correspondence: cslim@snu.ac.kr; kaang@snu.ac.kr

Department of Biological Sciences, College of Natural Sciences, Seoul

National University, 1 Gwanangno, Gwanak-gu, Seoul 08826, South Korea patient are not always convergent. Moreover, repetitive behaviors appear in many other neurodevelopmental and neuropsychiatric disorders [5]. Therefore, it is hard to distinguish repetitive behaviors of ASD patients from those of other neuropsychiatric disorders, like obsessive-compulsive disorder (OCD) [6]. However, as the diagnostic criteria implying, the repetitive behaviors of ASD patients may be related with social deficits. Supporting this, some treatments that rescued social deficits could restore repetitive behaviors, too. For example, oxytocin, a neuropeptide, promoted social interaction while reducing repetitive behaviors of ASD patients [7, 8].

Today, ASD draws global attention as the number of people diagnosed has rapidly increased. According to epidemiological studies, the current prevalence of autism is estimated to be $10-30$ per 10,000 people, with ASD occurring in an estimated 69.5 per 10,000 people [9]. Specifically, a study reported that the prevalence of ASD in Asia was as high as 264 per 10,000 people (about one out of 38 people) [10]. Among psychiatric diseases, 
this is relatively high incidence rate, which is why many researchers and clinicians are trying to understand the pathophysiology of ASD.

Since the direct analysis of human patients is difficult for in vivo and biochemical experiments, ASDs are currently studied using animal models. Among the available model organisms, mouse models are most commonly used in ASD researches, because of the ease of genetic manipulation, high accessibility, and relatively high similarity to humans. A number of transgenic ASD mouse models have been generated based on genomic studies of patients with ASD, the findings from which indicate that genomic components underlie the various ASD phenotypes [11-15]. They display various types of repetitive behaviors [11-13, 16, 17], and mice with a higher level of stereotyped behaviors also display more restricted behavioral patterns and diminished flexibility in learning, reversal learning, and extinction tasks $[18,19]$.

Although many scientists have explored the mechanisms of repetitive behaviors, the specific genetic and molecular factors underlying these repetitive behaviors and how they interact with each other in distinct brain regions are yet to be elucidated. Each characteristic repetitive behavior seems to stem from different molecular mechanisms and distinct neuronal pathways. In this review, we summarize the types of repetitive behaviors and neurophysiological properties of them associated with different ASD mouse models and compare the functions of affected genes for repetitive behaviors within each brain region. This review should aid in the understanding of the molecular and circuitry mechanisms underlying repetitive behaviors in ASD and contribute to the development of effective and targeted therapies for the repetitive behaviors associated with ASD.

\section{Repetitive behaviors of ASD mouse models}

A detailed understanding of the neural mechanisms underlying ASD is hampered by its complexity and heterogeneity. ASD is associated with abnormalities in various brain regions such as the neocortex, hippocampus, amygdala, and basal ganglia, which mediate social interaction, communication and repetitive behaviors.

Focusing on repetitive behaviors [20], despite the lack of specific criterion to define each repetitive behavioral category, according to Turner, repetitive behavior should be repeated at a relatively high rate, pursued in an invariant way, and considered inappropriate and abnormal in its manifestation and display. For example, just opening and closing a door to enter a room is not regarded as a repetitive behavior, even though the behavior is normally repeated every day. However, if someone open and close a door continuously without a specific purpose, then it could be classified as a repetitive behavior. Thus, a repetitive behavior can be heterogeneous depending on its characteristics and circumstances. Similarly, ASD mouse models also show several types of stereotyped repetitive behaviors including self-grooming, jumping, circling and marble burying. Example movies of each behavior are available in the previously published papers [12, 21-23]. A specific repetitive behavior of an ASD mouse model would depend on the characteristic abnormal physiological features resulting from an altered gene expression or a modification of a gene product. The detailed characteristics of ASD mouse models are summarized in (Table 1).

Although the ASD mouse models show a variety of alterations in molecular level, including metabotropic glutamate receptor 5 (mGluR5), $N$-methyl-D-aspartate glutamate receptor (NMDA-R) and $\gamma$-Aminobutyric acid receptor (GABA-R), a specific molecular pathway seems to be related with a specific repetitive behavior. Dopamine also could affect a repetitive behavior by modulating dopamine receptors in the striatum (Table 1).

\section{Self-grooming}

Mice normally scratch and brush their hair with their forelimbs for a few seconds to minutes. However, when the self-grooming behavior is repeated at a higher rate and a longer duration, it can be considered as a repetitive behavior. For example, BTBR $\mathrm{T}+\mathrm{tf} / \mathrm{J}$ (BTBR) mice, an inbred strain without corpus callosum, are used as a model of idiopathic autism with an increased rate of repetitive self-grooming [24]. This excessive self-grooming was rescued by inhibiting mGluR5 activity $[25,26]$. Many transgenic mouse models of ASD also display repetitive and excessive self-grooming and the functions of many neurotransmitters are implicated in this behavior (Table 1). For example, GABA-R agonists reduce repetitive self-grooming in BTBR mice without sedation $[13,27]$. Abnormal self-grooming also occurs in mice with contactin-associated protein-like 2 (Cntnap2) $^{-1-}$ mice, which was also rescued by treatment with risperidone, an antagonist to the dopamine D2 receptor (D2R) [28]. While we do not yet know the exact mechanisms underlying repetitive self-grooming, we do know that it is associated with multiple brain regions including the cortex, hypothalamus, striatum, cerebellum and amygdala [29-31].

\section{Jumping}

Another repetitive behavior observed in rodent ASD models is jumping. Most mice including C57BL/6 mice, a normal control mouse frequently used in behavioral researches sometimes jump using their hind limbs. In contrast with $\mathrm{C} 57 \mathrm{BL} / 6$ mice, the $\mathrm{C} 58 / \mathrm{J}$ mice are characterized by excessive jumping [32]. Interestingly, 


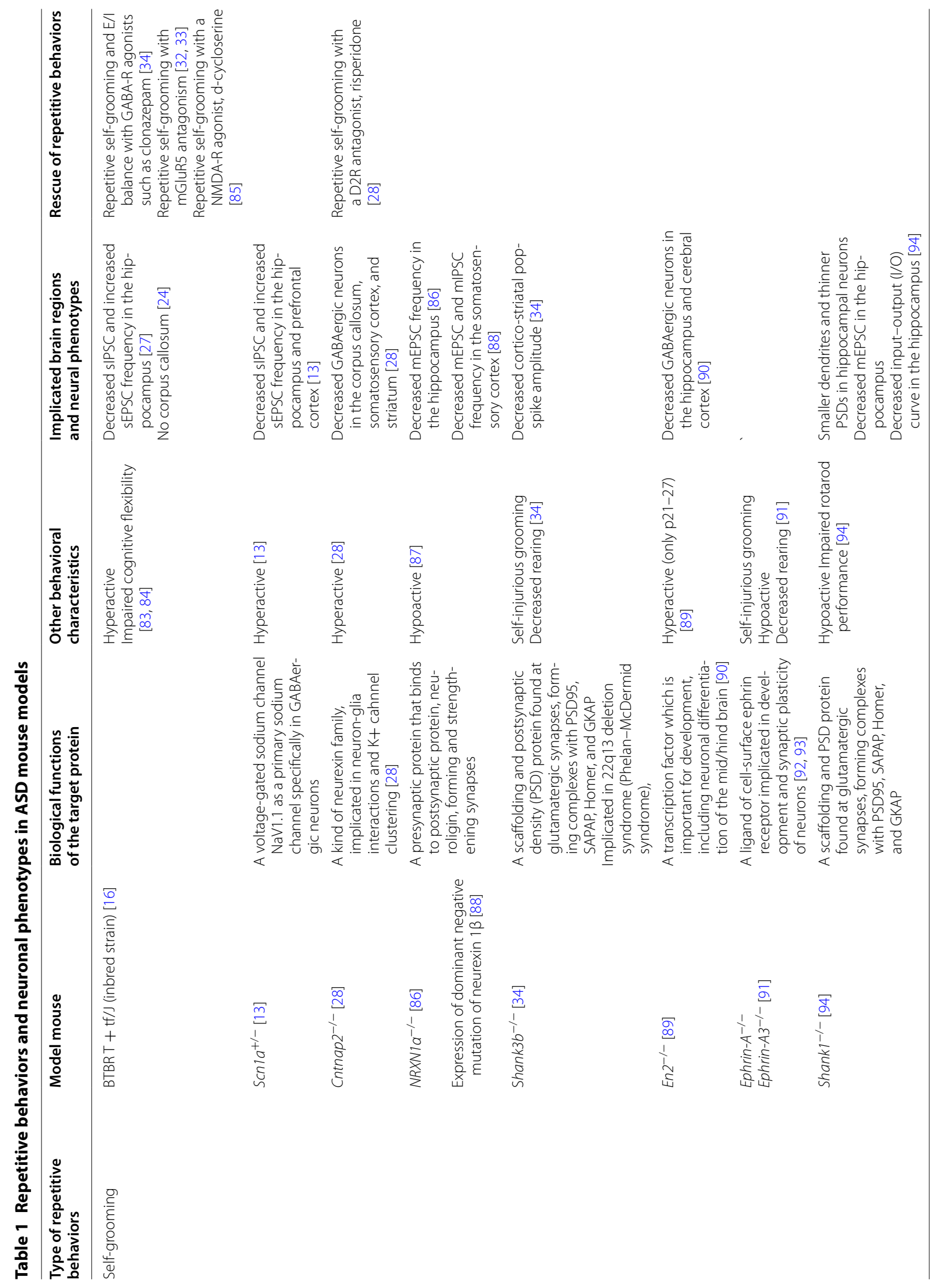




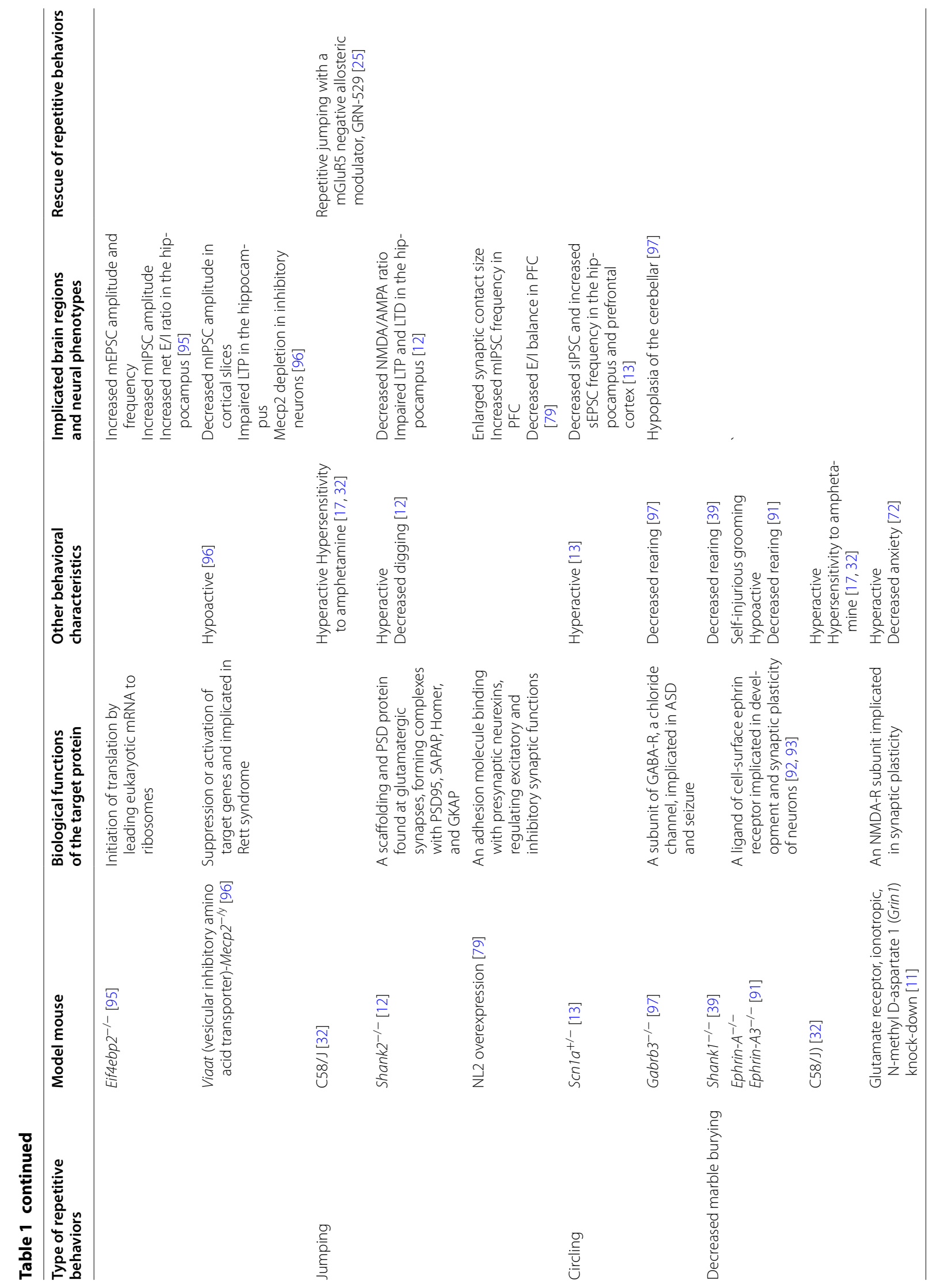




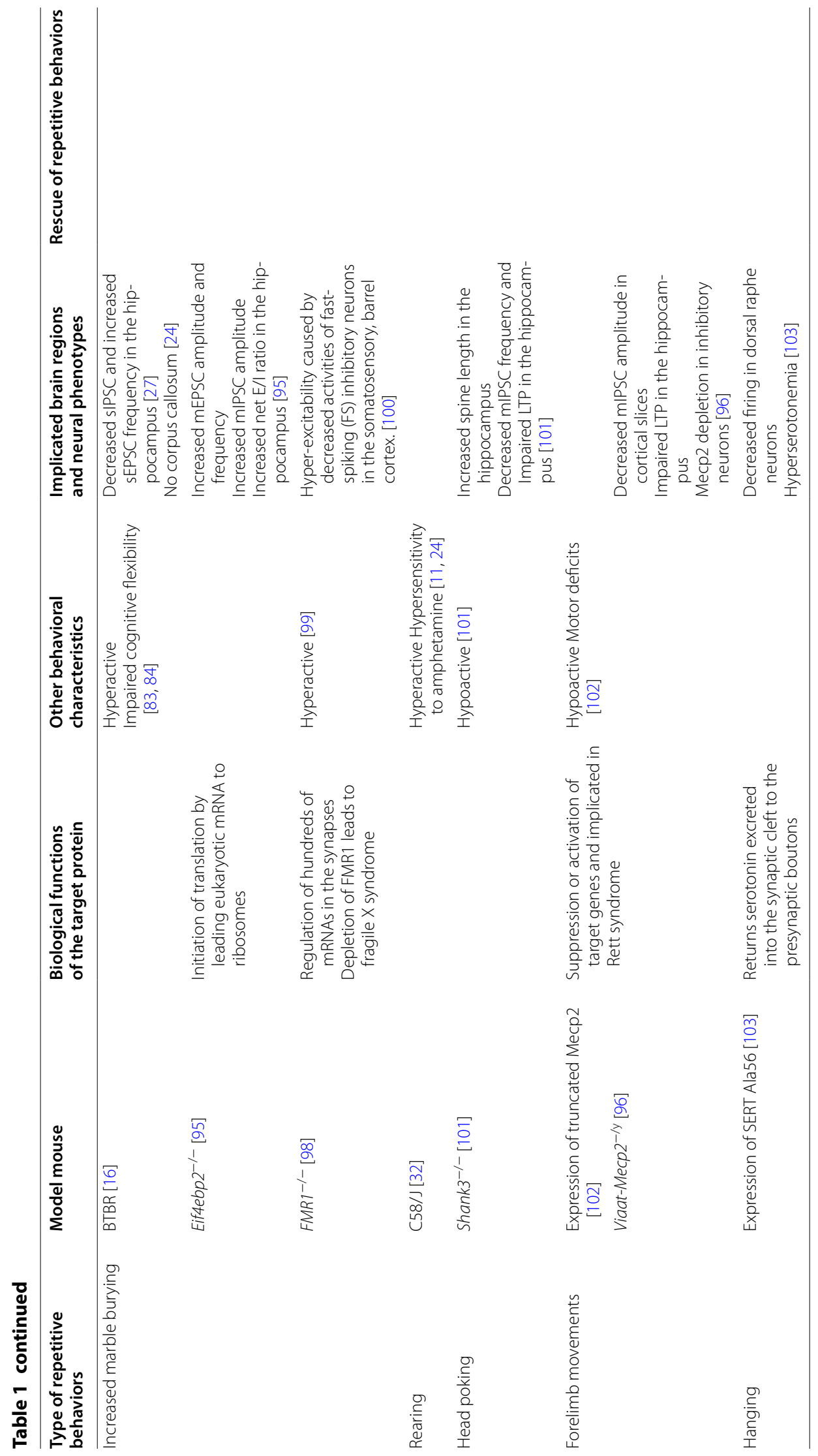


while $\mathrm{SH} 3$ and multiple ankyrin repeat domains $3 \mathrm{~b}$ $(\text { Shank } 3 b)^{-1-}$ mice display repetitive grooming, the Shank $2^{-1-}$ mice exhibit repetitive jumping and scrabbling behaviors (Table 1), despite the functional similarities between Shank3 and Shank2 proteins. Both proteins are enriched in excitatory synapses as scaffolding proteins, and their deficiency reduces NMDA-R activity $[12,33]$. However, only Shank3, but not Shank2, is highly expressed in the cerebellum and striatum, implicating different functions of the two proteins in distinct brain regions [34]. Interestingly, inhibition of mGluR5 signaling through GRN-529, a negative allosteric modulator of mGluR5, reduces the jumping behavior of $\mathrm{C} 58 / \mathrm{J}$ mice [24]. NMDA-R hyperfunction may be responsible for triggering the jumping observed in C58/J mice, because inhibition of mGluR5 signaling can alter NMDA-R activity and both receptors are tightly connected in the postsynaptic density (PSD).

\section{Circling}

Some ASD mice repeatedly rotate in fixed locations, in a circular pattern. Dopaminergic pathways from the striatum to the substantia nigra (SN) are implicated in mediating the circling behaviors, and an imbalance in striatal dopamine activity is thought to be a cause of the abnormal circling behaviors [35-37]. The direction of rotation seems to be contralateral to the brain region with high striatal dopaminergic activity. For example, when the dopamine D1 receptor (D1R) agonist, A68930, was injected in the striatum of one hemisphere of Bronx Waltzer mice, which show repetitive circling behaviors, their contralateral rotation increased while their ipsilateral rotation decreased [37].

Since alterations in GABA levels can also impair the homeostatic activity levels in the brain, GABA may also affect circling behaviors. For example, muscimol, a GABA-R agonist, injected into the substantia nigra pars reticulata $(\mathrm{SNr})$ induced a repetitive circling behavior [36].

\section{Marble burying}

Marble burying is the behavior of burying marbles scattered on the bedding into the bedding. It is a little controversial to categorize marble burying as a repetitive behavior, since the behavior is associated with anxiety to a novel context and exploration. Consistent with this, some ASD mouse models show increased marble burying behavior, while others demonstrate a decrease (Table 1). Interestingly, some mice with increased marble burying also exhibit increased locomotor activity, while other mice with decreased marble burying exhibit decreased locomotor activity $[38,39]$. This suggests the possibility of an overlap between the neuronal circuits involved with digging behavior and locomotor activity. In addition, several antidepressants/anxiolytics such as fluvoxamine, bupropion, and diazepam reduced both marble burying and digging [40]. Furthermore, minocycline, which shows an anxiolytic effect on Fragile X mental retardation 1 ( $F m r 1)$ KO mice, also reduced the elevated marble burying in these mice. Thus, the emotional states and brain circuitry involved with anxiety or depression may also affect marble burying behaviors.

\section{Hyperactivity}

Hyperactivity itself is not generally considered as a repetitive behavior, but the phenotype is often accompanied by repetitive body movements. Moreover, several ASD mouse models exhibit hyperactivity (Table 1 ). Supporting the relationship between repetitive behaviors and hyperactivity, local field potential recordings in several interconnected brain regions of norepinephrine-deficient mice, which display hyperactivity and repetitive grooming, indicated an impaired coherence across the corticostriatal circuits [41].

Other ASD mouse models in addition to the aforementioned mouse models, show additional repetitive behaviors, including rearing, head poking, forelimb movements and hanging (Table 1).

\section{General neural circuits of repetitive behaviors}

Various brain regions and pathways govern repetitive behaviors; however, the most notable pathway is the cortico-basal ganglia-thalamic pathway (Fig. 1a), which is also involved in the motor activities [42, 43]. For example, human brain imaging studies showed the positive correlation between the volume of basal ganglia compartments such as striatum, and degree of repetitive behavior in ASD patients [44]. In case of animal studies, injecting L-DOPA, a dopamine precursor, and apomorphine, a non-selective dopamine agonist, into the striatum of rats induced stereotypic gnawing behaviors [45]. In addition, a study demonstrated that Shank $3 b^{-1-}$ mice, which have abnormal self-grooming behavior, exhibited a reduced cortico-striatal synaptic transmission in medium spiny neurons (MSNs) [34].

The cortico-basal ganglia-thalamic pathway primarily consists of direct D1R-expressing and indirect D2R-expressing pathways (Fig. 1a). D1R-expressing GABAergic neurons in the direct pathway inhibit the internal globus pallidus (GPi) and substantia nigra pars reticulata (SNr). Sequentially, the GABAergic output from GPi to SNr inhibits thalamus and in turn thalamus activates the motor cortex. Thus, the final consequence of direct pathway is activation of movements. In contrast, D2R-expressing neurons inhibit the external globus pallidus (GPe) and GPe inhibits subthalamic nucleus (STN). 
The STN then activates GPi and SNr, which inhibits thalamus. Hence, the final consequence of indirect pathway is inactivation of movements and possibly affects repetitive behaviors of ASD mouse models. For example, mouse models of 16p11.2 deletion, which occupies relatively high incidence in ASD patients, show decreased grooming, accompanied with increased numbers of D2R-expressing striatal medium spiny neurons (MSNs) and increased spontaneous EPSC in the neurons [46, 47]. Interestingly, these mouse lines also showed increased hanging and circling, suggesting different regulatory mechanisms in indirect pathway among grooming, hanging and circling [47].

It is thought that sub-pathways of the cortico-basal ganglia-thalamic circuit and the dynamic molecular regulation in the sub-pathways are responsible for each class of repetitive behaviors [48-50]. For example, intrastriatal injection of a D1R antagonist, SCH23390, or an NMDA-R antagonist, MK-801, in deer mouse, a wellknown jumping mouse, reduced repetitive jumping [51], while injecting apomorphine induced stereotypic grooming and hyperactivity without affecting the jumping [52]. Similarly, chronic administration of the selective serotonergic reuptake inhibitor (SSRI), escitalopram, attenuated the horizontal repetitive movements characteristic of deer mice, without affecting the vertical repetitive movements including jumping, implicating a differential regulation of jumping and other repetitive behaviors [53].

Furthermore, previously uncovered connections related to the cortico-basal ganglia-thalamic circuits are discovered recently. For example, the inhibitory projections, with or without acetylcholine, from external globus pallidus (GPe) to frontal cortex were found [54]. In addition, the same research group demonstrated that a noncanonical function of D2R-expressing neurons in indirect pathway, which activates the motor cortex temporally, suggesting more heterogeneity in the circuits than we expected [55].

An interesting feature of ASD mouse models is that observed abnormal synaptic functions have mostly been found in the hippocampus. In spite of the lack of evidence showing the causal relationship between hippocampus and repetitive behaviors, stimulation of ventral hippocampus with NMDA increased locomotor activity, while its inhibition decreased the locomotor activity $[56,57]$. In addition, the hippocampus has connections to several brain regions in cortico-basal ganglia-thalamic circuits, including striatum and amygdala, suggesting the possibility that the hippocampus affects the cortico-basal ganglia-thalamic circuits and possibly repetitive behaviors [58-64].

\section{Pharmacological rescues of repetitive behaviors}

In spite of the limited understanding of the causes of repetitive behaviors, some repetitive behaviors of ASD mouse models were rescued by administering specific treatments. In particular, pharmacological treatments that manipulate the neuronal activity involved in repetitive behaviors are the most salient treatment methods because of their potential to be applied in therapies for human ASD patients.

For this reason, a series of drugs have been tested for ASD mouse models, some of which successively reduced the repetitive behaviors of the mice. Among the many ASD mouse models, the BTBR mice is one of the most frequently studied models and several drugs have reduced their repetitive self-grooming without sedation effects, as we mentioned earlier (Table 1). Their self-grooming was reduced by mGluR5 antagonists or GABA-R agonists [25-27, 65]. Although the involvement of its mechanisms in repetitive behaviors remains unclear, inhibition of mGluR5 expression could activate D1R signaling by stimulating the PKA activity. Accordingly, mGluR5 antagonism possibly inhibits the direct pathway of the cortico-basal ganglia-thalamic circuit [66] (Fig. 1b). In addition, the knockdown of mGluR5 in D1Rexpressing cells reduced locomotion activity, supporting the idea [67]. Meanwhile, GABA-R agonists may reduce elevated excitatory/inhibitory (E/I) balance, rescuing overactivation of the motor cortical area, where the final signal of the cortico-basal ganglia-thalamic circuit arrives (Fig. 1b) For example, repetitive behaviors induced by amphetamine was attenuated by GABA-R agonists [68]. In addition, $F m r 1^{-/-}$mice showed hyperexcitability caused by decreased activities of fast-spiking (FS) inhibitory neurons in the somatosensory and barrel cortex, and a GABA-R agonist that reduced the self-grooming of BTBR mice also reduced the locomotor activity and repetitive marble burying of $\mathrm{Fmrl}^{-/-}$mice. Moreover, a human fMRI study also reported that the GABA concentration in the supplementary motor area (SMA) was inversely correlated with the excitability of the motor cortex, supporting the relationship between GABAergic function in cortical areas and repetitive behaviors [69].

Another type of drug that reduces repetitive selfgrooming is risperidone, which modulates various molecular targets but primarily blocks the D2R, resulting in reduced activity of the indirect pathway. However, reduced activity of the indirect pathway is generally thought to increase repetitive behaviors. Thus, the effect of risperidone, which reduces the repetitive self-grooming of Cntnap $2^{-1-}$ mice is somewhat paradoxical. However, it is interesting that systemic injection of haloperidol, a D2R antagonist, also reduced movements and activities of the motor cortex of rats [70]. In addition, D2R overexpression in the striatum enhanced the GABAergic function of the prefrontal cortex (PFC), reducing the excitability of PFC [71]. These results 
suggest that reduced self-grooming by risperidone may be attributed to the enhancement of GABAergic inhibition of the cortex (Fig. 1b).

\section{Hub brain regions implicated in both social and repetitive behaviors}

Since the main symptoms of ASD are impairments in social interactions and repetitive behaviors, it may be reasonable to postulate a hub brain region that links the social behaviors and repetitive behaviors. Supporting this view, amygdala may be the most notable candidate region specifically involved in self-grooming. Activation of a population of vesicular glutamate transporter 2 (vGLUT2)-positive glutamatergic neurons in the medial amygdala (MeA) of mice promoted self-grooming while suppressing social interaction. On the other hand, the activation of vesicular GABA transporter (vGAT)-positive GABAergic neurons in the MeA triggered social interaction while suppressing self-grooming [31]. In addition, when the glutamatergic projection from basolateral amygdala (BLA) to the ventral hippocampus of mice was activated, social interaction was reduced while

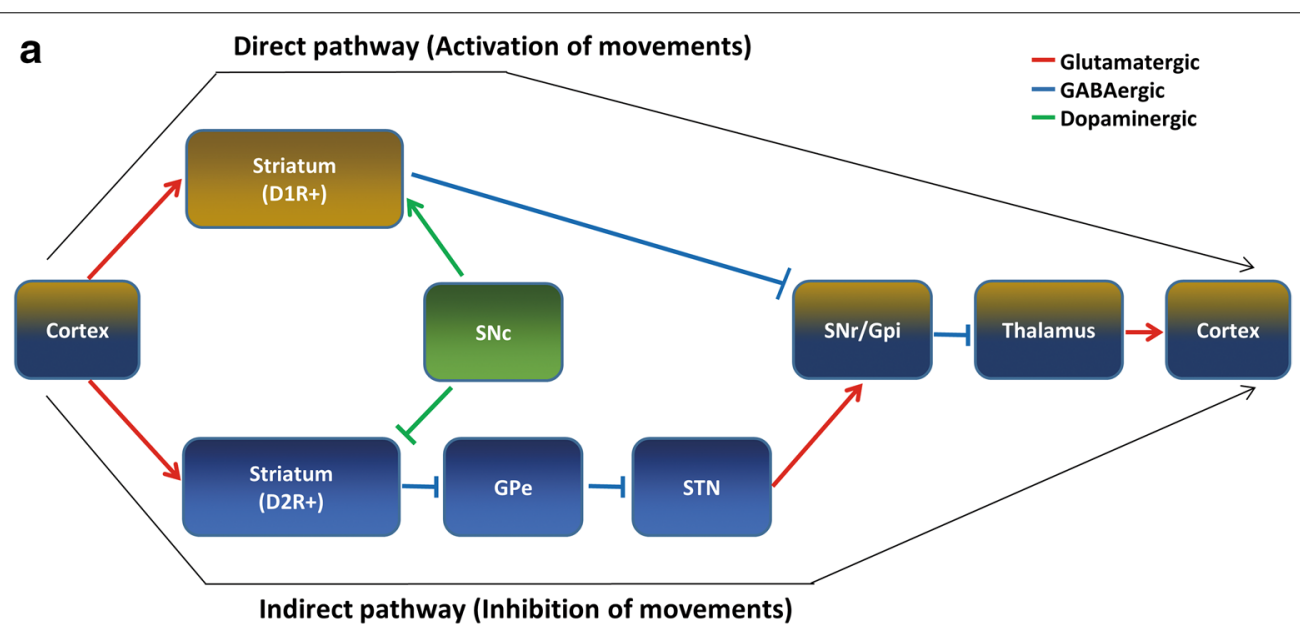

b

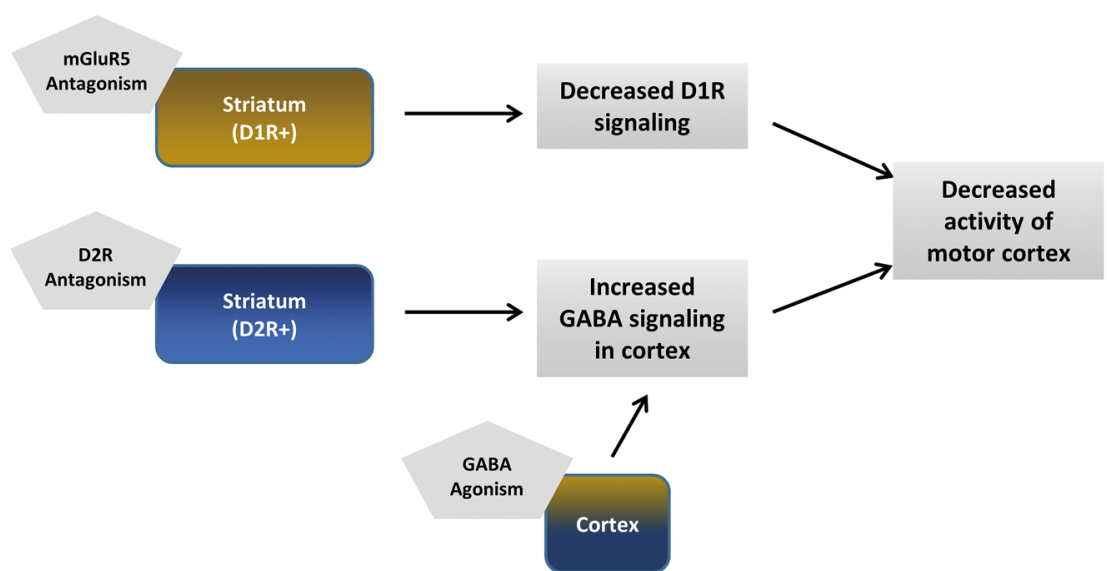

Fig. 1 Neural pathways implicated in repetitive behaviors. a Schematic drawings of the cortico-basal ganglia-thalamic pathways including the direct and indirect pathways. The direct pathway is represented by brown color, while the indirect pathway is represented by blue color. The regions that are common in both pathways are represented with mixed brown and blue colors. Dopaminergic sources from substantia nigra pars compacta $(\mathrm{SNc})$, which activate and inactivate direct and indirect pathways, respectively, are represented by green color. The projections from cortex activate both D1R and D2R-expressing GABAergic neurons in the striatum. Then, the D1R-expressing GABAergic neurons in the direct pathway inhibit the internal globus pallidus (GPi) and substantia nigra pars reticulata (SNr). Sequentially, the GABAergic output from GPi and SNr inhibits thalamus and in turn thalamus activates the motor cortex. Thus, the final consequence of the direct pathway is activation of movements. In contrast, D2R-expressing neurons in the indirect pathway inhibit the external globus pallidus (GPe) and GPe inhibits subthalamic nucleus (STN). The STN then activates GPi and SNr, which inhibits thalamus. Hence, the final consequence of indirect pathway is inactivation of movements. b Possible neuronal mechanisms of pharmacological rescue of repetitive behaviors. mGluR5 antagonism can inhibit the direct pathway by inhibiting the D1R signaling. GABA agonists can ameliorate elevated E/I balance in the motor cortex of some ASD mouse models, and D2R antagonism may potentiate the GABAergic function in cortical areas 
the self-grooming increased [61] (Fig. 2). Thus, it is possible that amygdalo-hippocampal pathway may be highly activated in ASD mouse models.

PFC also can modulate both social and repetitive behaviors. PFC has a projection to the substantia nigra pars compacta $(\mathrm{SNc})$, a dopaminergic source of the striatum. When the projection was activated, it induced hyperactivity and repetitive movement behaviors of mice due to hyperdopaminergia in the striatum [72] (Fig. 2). Moreover, the proper level of dopamine in PFC seems to be required for preventing repetitive behaviors. For example, when an antagonist of dopamine D2 and D3 receptors, sulpiride was injected unilaterally into the PFC of rats pretreated with amphetamine, it induced ipsiversive circling [73]. In another study, after sensitization to cocaine, cocaine injection in rats induced stereotypy with increased PFC dopamine release and decreased the activity of both inhibitory and excitatory projection from medial PFC (mPFC) to SNr [74].

Besides the involvement in repetitive behaviors, PFC also affects social behaviors. For example, lateral prefrontal cortex (LPFC) is important for social information processing and early damage of PFC resulted in impairment of social behaviors [75, 76]. Furthermore, optogenetic activation of $\mathrm{mPFC}$ increased $\mathrm{E} / \mathrm{I}$ balance in that region and impaired social behaviors of the mice [77] (Fig. 2).
Indeed, ASD mouse models often show abnormalities in their PFC. Scn $1 a^{+/-}$mouse, one of autistic mice, showed increased E/I balance in PFC [13]. Another autistic mouse, $\mathrm{Fmrl}^{-/-}$mouse, showed hyperconnectivity of layer 5 pyramidal neurons in $\mathrm{mPFC}$ [78]. In addition, Neuroligin 2 (NL2) overexpression in PFC of mice increased mIPSC frequency and repetitive jumping, and impaired social behavior of the mice [79]. Thus, impairment in PFC may also cause autistic symptoms in subpopulation of patients.

Ventral tegmental area (VTA) is also responsible for both social and repetitive behaviors. According to a study, after being sensitized to cocaine, VTA glutamate release was increased. This glutamate increase and cocaineinduced stereotypy were rescued by SCH-23390, a D1R antagonist, infusion into VTA [80]. In addition, blocking non-NMDA-R-mediated glutamatergic transmission from PFC to VTA reduced increased self-grooming of rats that was induced by an NMDA-R antagonist, phencyclidine (PCP) [81] (Fig. 2). Since VTA has a dopaminergic projection to $\mathrm{PFC}$, it is likely that the regulation of glutamatergic transmission in PFC by VTA dopaminergic neurons may be important for repetitive self-grooming and motor activities.

As to social behaviors, activity of the dopaminergic projection from VTA to Nucleus Accumbens (NAc), was

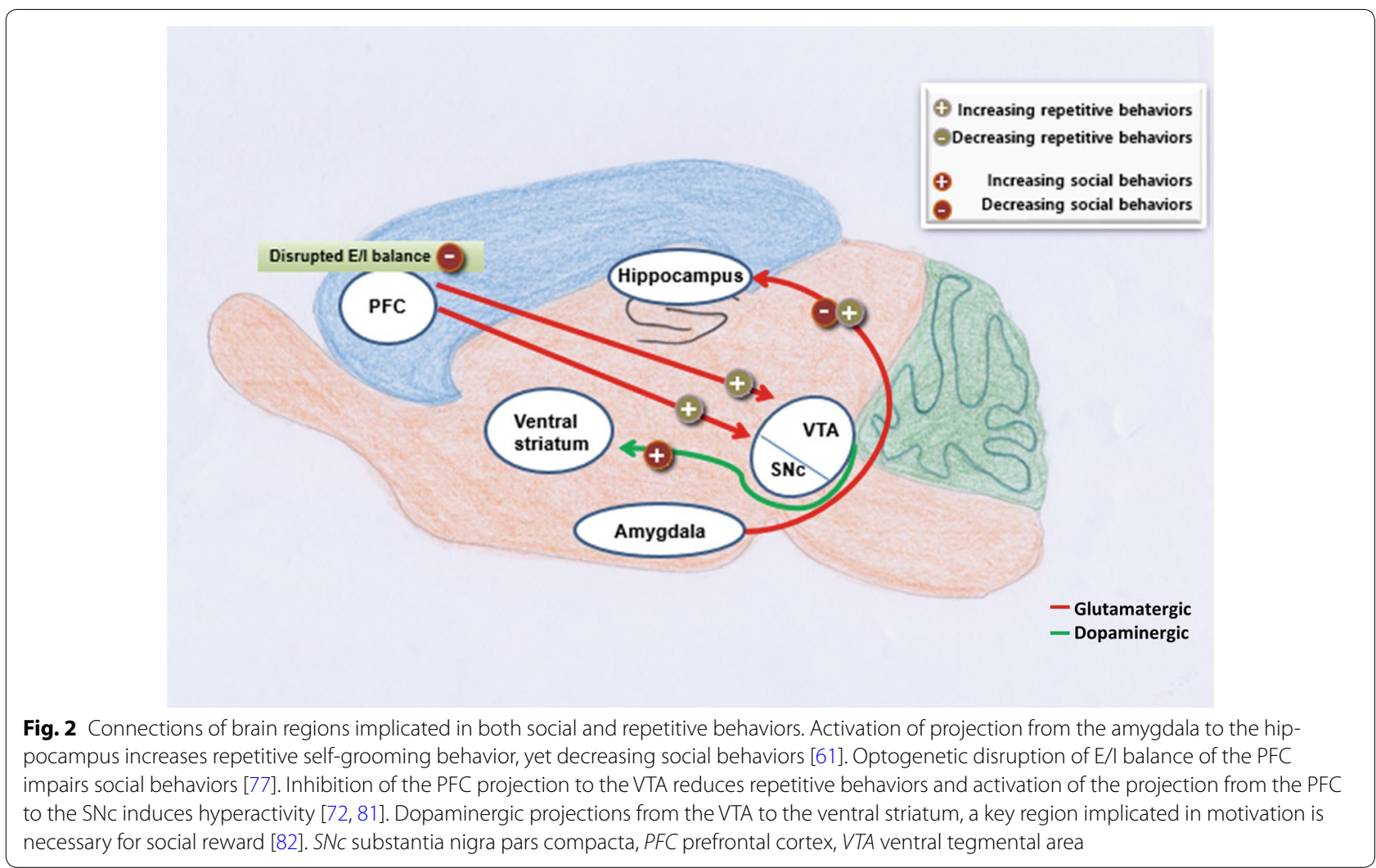


increased when a mouse confronted with a social objects. Furthermore, optogenetic activation or inhibition of this projection increased or decreased the social interaction time for the subject mice [82]. Thus, abnormal dopaminergic activities in the NAc possibly impair social behaviors and generate repetitive behaviors of ASD mouse models.

\section{Conclusion}

We have discussed the general features of ASD and one of its main symptoms, repetitive behaviors. We then summarized the transgenic or inbred ASD mouse models and their phenotypes focusing on specific repetitive behaviors, electrophysiological properties, and neuronal circuit abnormalities. And then, we summarized pharmacological interventions that used to reduce repetitive behaviors in ASD mouse models. Finally, we discussed hub brain regions possibly involved in both social and repetitive behaviors.

Despite the many studies using ASD mouse models, it is still difficult to identify the brain networks responsible for each repetitive behavior. Moreover, physiological properties of mice with repetitive behaviors are not convergent even in mice with the same repetitive behavior. Although the causal relationships have not yet been proven, organizing the results of the studies provides a glimpse into the relationship between the different brain regions and the corresponding abnormal synaptic properties and repetitive behaviors associated with various ASD mouse models.

Further research should be conducted to investigate the neuronal abnormalities in specific brain regions associated with the repetitive behaviors in ASD mouse models. For that reason, it would be helpful to study the microcircuitry of ASD mouse models in more detail by manipulating specific neuronal populations using pharmacological drugs and conditional $\mathrm{KO}$ or optogenetics that currently used in broad brain research area. By doing so, understanding neuronal mechanisms of the repetitive behaviors in ASD would be also helpful to find safer and more effective treatments for each patient with ASD, in a situation that an efficient treatment for ASD symptoms is limiting.

\footnotetext{
Abbreviations

BLA: basolateral amygdala; BTBR: BTBR T + tf/J; Cntnap2: contactin-associated protein-like 2; D1R: dopamine D1 receptor; D2R: dopamine D2 receptor; DSM5: diagnostic and statistical manual of mental disorders; Eif4ebp2: eukaryotic translation initiation factor 4E-binding protein 2; Fmr1: fragile X mental retardation 1; GABA: $\gamma$-Aminobutyric acid; Gabrb3: gamma-aminobutyric acid receptor subunit $\beta$-3; Grin 1: glutamate receptor, ionotropic, N-methyl D-aspartate 1; MeA: medial amygdala; Mecp2: methyl CpG binding protein 2; mGluR5: metabotropic glutamate receptor 5; NMDA-R: N-methyl-D-aspartate glutamate receptor; PSD: postsynaptic density; RBS: repetitive behavior subscales; Scn1a: sodium channel, voltage-gated, type 1a; SERT: serotonin transporter; Shank: SH3 and multiple ankyrin repeat domains; SNpc: substantia
}

nigra pars compacta; vGAT: vesicular GABA transporter; vGLUT2: vesicular glutamate transporter 2; Viaat: vesicular inhibitory amino acid transporter.

\section{Authors' contributions}

HK drafted the manuscript. CSL and BKK contributed to organizing the contents of ASD mouse models and writing the paper. All authors read and approved the final manuscript.

\section{Acknowledgements}

This study was supported by the National Honor Scientist Program (2012R1A3A1050385) funded by the National Research Foundation (NRF) of Korea.

\section{Competing interests}

The authors declare that they have no competing interests.

Received: 25 August 2015 Accepted: 5 January 2016

Published online: 20 January 2016

\section{References}

1. Koh JY, Lim JS, Byun HR, Yoo MH. Abnormalities in the zinc-metalloprotease-BDNF axis may contribute to megalencephaly and cortical hyperconnectivity in young autism spectrum disorder patients. Mol Brain. 2014. doi:10.1186/s13041-014-0064-z.

2. Rogers SJ, Ozonoff S. Annotation: what do we know about sensory dysfunction in autism? A critical review of the empirical evidence. J Child Psychol Psychiatry. 2005;46(12):1255-68.

3. Lai MC, Lombardo MV, Baron-Cohen S. Autism. Lancet. 2014;383(9920):896-910.

4. Gillberg C, Billstedt E. Autism and Asperger syndrome: coexistence with other clinical disorders. Acta Psychiatr Scand. 2000;102(5):321-30.

5. Chris Plauche J. Early clinical characteristics of children with autism. In: autistic spectrum disorders in children. Informa Healthcare; 2004.

6. Zandt F, Prior M, Kyrios M. Repetitive behaviour in children with high functioning autism and obsessive compulsive disorder. J Autism Dev Disord. 2007;37(2):251-9. doi:10.1007/s10803-006-0158-2.

7. Hollander E, Novotny S, Hanratty M, Yaffe R, DeCaria CM, Aronowitz $B R$, et al. Oxytocin infusion reduces repetitive behaviors in adults with autistic and Asperger's disorders. Neuropsychopharmacology. 2003;28(1):193-8.

8. Andari E, Duhamel JR, Zalla T, Herbrecht E, Leboyer M, Sirigu A. Promoting social behavior with oxytocin in high-functioning autism spectrum disorders. Proc Natl Acad Sci USA. 2010;107(9):4389-94. doi:10.1073/ pnas.0910249107.

9. Tsai LY. Impact of DSM-5 on epidemiology of Autism Spectrum Disorder. Res Autism Spectr Disord. 2014;8(11):1454-70.

10. Kim YS, Leventhal BL, Koh YJ, Fombonne E, Laska E, Lim EC, et al. Prevalence of autism spectrum disorders in a total population sample. Am J Psychiatry. 2011;168(9):904-12. doi:10.1176/appi.ajp.2011.10101532.

11. Amir RE, Van Den Veyver IB, Wan M, Tran CQ, Francke U, Zoghbi HY. Rett syndrome is caused by mutations in X-linked MECP2, encoding methylCpG-binding protein 2. Nat Genet. 1999;23(2):185-8.

12. Won H, Lee HR, Gee HY, Mah W, Kim Jl, Lee J, et al. Autistic-like social behaviour in Shank2-mutant mice improved by restoring NMDA receptor function. Nature. 2012;486(7402):261-5.

13. Han S, Tai C, Westenbroek RE, Yu FH, Cheah CS, Potter GB, et al. Autisticlike behaviour in Scn1a +- mice and rescue by enhanced GABA-mediated neurotransmission. Nature. 2012;489(7416):385-90.

14. O'Roak BJ, Deriziotis P, Lee C, Vives L, Schwartz JJ, Girirajan S, et al. Exome sequencing in sporadic autism spectrum disorders identifies severe de novo mutations. Nat Genet. 2011;43(6):585-9.

15. Sanders SJ, Murtha MT, Gupta AR, Murdoch JD, Raubeson MJ, Willsey $\mathrm{AJ}$, et al. De novo mutations revealed by whole-exome sequencing are strongly associated with autism. Nature. 2012;484(7397):237-41.

16. McFarlane HG, Kusek GK, Yang M, Phoenix JL, Bolivar VJ, Crawley JN. Autism-like behavioral phenotypes in BTBRT $+\mathrm{tf} / \mathrm{J}$ mice. Genes Brain Behav. 2008;7(2):152-63. 
17. Moy SS, Riddick NV, Nikolova VD, Teng BL, Agster KL, Nonneman RJ, et al. Repetitive behavior profile and supersensitivity to amphetamine in the C58/J mouse model of autism. Behav Brain Res. 2014;259:200-14.

18. Garner JP, Mason GJ. Evidence for a relationship between cage stereotypies and behavioural disinhibition in laboratory rodents. Behav Brain Res. 2002;136(1):83-92.

19. Tanimura Y, Yang MC, Lewis MH. Procedural learning and cognitive flexibility in a mouse model of restricted, repetitive behaviour. Behav Brain Res. 2008;189(2):250-6.

20. Turner M. Towards an executive dysfunction account of repetitive behaviour in autism. Autism as an executive disorder, vol 8. Oxford: Oxford University Press; 1997.

21. Silverman JL, Yang M, Lord C, Crawley JN. Behavioural phenotyping assays for mouse models of autism. Nat Rev Neurosci. 2010;11(7):490502. doi:10.1038/nrn2851.

22. Angoa-Pérez M, Kane MJ, Briggs DI, Francescutti DM, Kuhn DM. Marble burying and nestlet shredding as tests of repetitive, compulsive-like behaviors in mice. J Vis Exp. 2013;82:50978.

23. Deisseroth K. Optogenetics: 10 years of microbial opsins in neuroscience. Nat Neurosci. 2015;18(9):1213-25. doi:10.1038/nn.4091.

24. Wahlsten D, Metten P, Crabbe JC. Survey of 21 inbred mouse strains in two laboratories reveals that BTBR T/+ tf/tf has severely reduced hippocampal commissure and absent corpus callosum. Brain Res. 2003;971(1):47-54.

25. Silverman JL, Smith DG, Rizzo SJS, Karras MN, Turner SM, Tolu SS, et al. Negative allosteric modulation of the MGluR5 receptor reduces repetitive behaviors and rescues social deficits in mouse models of autism. Sci Transl Med. 2012;4(131):131ra51.

26. Silverman JL, Tolu SS, Barkan CL, Crawley JN. Repetitive self-grooming behavior in the BTBR mouse model of autism is blocked by the mGluR5 antagonist MPEP. Neuropsychopharmacology. 2010;35(4):976-89.

27. Han S, Tai C, Jones CJ, Scheuer T, Catterall WA. Enhancement of inhibitory neurotransmission by GABAA receptors having a2,3-subunits ameliorates behavioral deficits in a mouse model of autism. Neuron. 2014;81(6):1282-9.

28. Peñagarikano O, Abrahams BS, Herman El, Winden KD, Gdalyahu A, Dong $\mathrm{H}$, et al. Absence of CNTNAP2 leads to epilepsy, neuronal migration abnormalities, and core autism-related deficits. Cell. 2011;147(1):235-46.

29. Berridge KC, Whishaw IQ. Cortex, striatum and cerebellum: control of serial order in a grooming sequence. Exp Brain Res. 1992;90(2):275-90.

30. Kruk MR, Westphal KGC, Van Erp AMM, Van Judith A, Cave BJ, Slater E, et al. The hypothalamus: cross-roads of endocrine and behavioural regulation in grooming and aggression. Neurosci Biobehav Rev. 1998;23(2):163-77.

31. Hong W, Kim DW, Anderson DJ. Antagonistic control of social versus repetitive self-grooming behaviors by separable amygdala neuronal subsets. Cell. 2014;158(6):1348-61.

32. Ryan BC, Young NB, Crawley JN, Bodfish JW, Moy SS. Social deficits, stereotypy and early emergence of repetitive behavior in the $\mathrm{C58} / \mathrm{J}$ inbred mouse strain. Behav Brain Res. 2010;208(1):178-88.

33. Duffney LJ, Wei J, Cheng J, Liu W, Smith KR, Kittler JT, et al. Shank3 deficiency induces NMDA receptor hypofunction via an actin-dependent mechanism. J Neurosci. 2013;33(40):15767-78.

34. Peça J, Feliciano C, Ting JT, Wang W, Wells MF, Venkatraman TN, et al. Shank3 mutant mice display autistic-like behaviours and striatal dysfunction. Nature. 2011:472(7344):437-42.

35. Vaccarino FJ, Franklin KBJ. Dopamine mediates ipsi- and contraversive circling elicited from the substantia nigra. Pharmacol Biochem Behav. 1982;17(3):431-4

36. Velíšek L, Velíšková J, Ravizza T, Giorgi FS, Moshé SL. Circling behavior and (14C)2-deoxyglucose mapping in rats: possible implications for autistic repetitive behaviors. Neurobiol Dis. 2005;18(2):346-55

37. Ishiguro A, Inagaki M, Kaga M. Stereotypic circling behavior in mice with vestibular dysfunction: asymmetrical effects of intrastriatal microinjection of a dopamine agonist. Int J Neurosci. 2007;117(7):1049-64.

38. Balemans MCM, Huibers MMH, Eikelenboom NWD, Kuipers AJ, van Summeren RCJ, Pijpers MMCA, et al. Reduced exploration, increased anxiety, and altered social behavior: autistic-like features of euchromatin histone methyltransferase 1 heterozygous knockout mice. Behav Brain Res. 2010;208(1):47-55.

39. Sungur AÖ, Vörckel KJ, Schwarting RKW, Wöhr M. Repetitive behaviors in the Shank1 knockout mouse model for autism spectrum disorder: developmental aspects and effects of social context. J Neurosci Methods. 2014;234:92-100. doi:10.1016/j.jneumeth.2014.05.003.

40. Hayashi E, Kuratani K, Kinoshita M, Hara H. Pharmacologically distinctive behaviors other than burying marbles during the marble burying test in mice. Pharmacology. 2010;86(5-6):293-6. doi:10.1159/000321190.

41. Dzirasa K, Phillips HW, Sotnikova TD, Salahpour A, Kumar S, Gainetdinov $\mathrm{RR}$, et al. Noradrenergic control of cortico-striato-thalamic and mesolimbic cross-structural synchrony. J Neurosci. 2010;30(18):6387-97. doi:10.1523/JNEUROSCI.0764-10.2010.

42. Garner JP. Stereotypies and other abnormal repetitive behaviors: potential impact on validity, reliability, and replicability of scientific outcomes. ILAR J. 2005;46(2):106-17.

43. Garner JP, Meehan CL, Mench JA. Stereotypies in caged parrots, schizophrenia and autism: evidence for a common mechanism. Behav Brain Res. 2003;145(1-2):125-34. doi:10.1016/S0166-4328(03)00115-3.

44. Calderoni S, Bellani M, Hardan AY, Muratori F, Brambilla P. Basal ganglia and restricted and repetitive behaviours in autism spectrum disorders: current status and future perspectives. Epidemiol Psychiatr Sci. 2014;23(3):235-8. doi:10.1017/S2045796014000171.

45. Ernst AM, Smelik PG. Site of action of dopamine and apomorphine on compulsive gnawing behaviour in rats. Experientia. 1966;22(12):837-8 doi:10.1007/BF01897450.

46. Horev G, Ellegood J, Lerch JP, Son YEE, Muthuswamy L, Vogel H, et al. Dosage-dependent phenotypes in models of 16p11.2 lesions found in autism. Proc Natl Acad Sci USA. 2011;108(41):17076-81. doi:10.1073/ pnas.1114042108.

47. Portmann T, Yang M, Mao R, Panagiotakos G, Ellegood J, Dolen G, et al. Behavioral abnormalities and circuit defects in the basal ganglia of a mouse model of 16p11.2 deletion syndrome. Cell Reports. 2014;7(4):1077-92.

48. Haber SN, Calzavara R. The cortico-basal ganglia integrative network: the role of the thalamus. Brain Res Bull. 2009;78(2-3):69-74.

49. Groenewegen HJ, Van Den Heuvel OA, Cath DC, Voorn P, Veltman DJ. Does an imbalance between the dorsal and ventral striatopallidal systems play a role in Tourette's syndrome? A neuronal circuit approach. Brain Dev. 2003;25(SUPPL. 1):S3-14.

50. Mason G, Rushen J. Stereotypic animal behaviour: fundamentals and applications to welfare. In: Stereotypic animal behaviour: fundamentals and applications to welfare. 2 nd ed. 2006.

51. Presti MF, Mikes HM, Lewis MH. Selective blockade of spontaneous motor stereotypy via intrastriatal pharmacological manipulation. Pharmacol Biochem Behav. 2003;74(4):833-9. doi:10.1016/ S0091-3057(02)01081-X.

52. Presti MF, Gibney BC, Lewis MH. Effects of intrastriatal administration of selective dopaminergic ligands on spontaneous stereotypy in mice. Physiol Behav. 2004;80(4):433-9. doi:10.1016/j.physbeh.2003.09.008.

53. Wolmarans DW, Brand L, Stein DJ, Harvey BH. Reappraisal of spontaneous stereotypy in the deer mouse as an animal model of obsessivecompulsive disorder (OCD): response to escitalopram treatment and basal serotonin transporter (SERT) density. Behav Brain Res. 2013;256:545-53. doi:10.1016/j.bbr.2013.08.049.

54. Saunders A, Oldenburg IA, Berezovskii VK, Johnson CA, Kingery ND, Elliott $\mathrm{HL}$, et al. A direct GABAergic output from the basal ganglia to frontal cortex. Nature. 2015;521(7550):85-9. doi:10.1038/nature14179.

55. Oldenburg lan A, Sabatini Bernardo L. Antagonistic but not symmetric regulation of primary motor cortex by basal ganglia direct and indirect pathways. Neuron. 2015;86(5):1174-81. doi:10.1016/j. neuron.2015.05.008.

56. Bast T, Zhang WN, Feldon J. The ventral hippocampus and fear conditioning in rats: different anterograde amnesias of fear after tetrodotoxin inactivation and infusion of the GABAA agonist muscimol. Exp Brain Res. 2001;139(1):39-52. doi:10.1007/s002210100746.

57. Zhang WN, Bast T, Feldon J. Effects of hippocampal N-methyl-D-aspartate infusion on locomotor activity and prepulse inhibition: differences between the dorsal and ventral hippocampus. Behav Neurosci. 2002;116(1):72-84. doi:10.1037/0735-7044.116.1.72.

58. Strange BA, Witter MP, Lein ES, Moser El. Functional organization of the hippocampal longitudinal axis. Nat Rev Neurosci. 2014;15(10):655-69. doi:10.1038/nrn3785.

59. Aggleton JP, O'Mara SM, Vann SD, Wright NF, Tsanov M, Erichsen JT. Hippocampal-anterior thalamic pathways for memory: 
uncovering a network of direct and indirect actions. Eur J Neurosci. 2010;31(12):2292-307. doi:10.1111/j.1460-9568.2010.07251.x.

60. Floresco SB, Todd CL, Grace AA. Glutamatergic afferents from the hippocampus to the nucleus accumbens regulate activity of ventral tegmental area dopamine neurons. J Neurosci. 2001;21(13):4915-22.

61. Felix-Ortiz AC, Tye KM. Amygdala inputs to the ventral hippocampus bidirectionally modulate social behavior. J Neurosci. 2014;34(2):586-95. doi:10.1523/JNEUROSCI.4257-13.2014.

62. Ciocchi S, Passecker J, Malagon-Vina H, Mikus N, Klausberger T. Selective information routing by ventral hippocampal CA1 projection neurons. Science. 2015;348(6234):560-3. doi:10.1126/science.aaa3245.

63. Mandyam CD. The interplay between the hippocampus and amygdala in regulating aberrant hippocampal neurogenesis during protracted abstinence from alcohol dependence. Front Psychiatr. 2013. doi:10.3389/fpsyt.2013.00061.

64. Feduccia AA, Chatterjee S, Bartlett SE. Neuronal nicotinic acetylcholine receptors: Neuroplastic changes underlying alcohol and nicotine addictions. Front Mol Neurosci. 2012. doi:10.3389/fnmol.2012.00083.

65. Silverman JL, Pride MC, Hayes JE, Puhger KR, Butler-Struben HM, Baker $S$, et al. GABA B receptor agonist $\mathrm{R}$-baclofen reverses social deficits and reduces repetitive behavior in Two mouse models of autism. Neuropsychopharmacology. 2015;40(9):2228-39. doi:10.1038/npp.2015.66.

66. Conn PJ, Battaglia G, Marino MJ, Nicoletti F. Metabotropic glutamate receptors in the basal ganglia motor circuit. Nat Rev Neurosci. 2005;6(10):787-98. doi:10.1038/nrn1763.

67. Parkitna JR, Sikora M, Gołda S, Gołembiowska K, Bystrowska B, Engblom $D$, et al. Novelty-seeking behaviors and the escalation of alcohol drinking after abstinence in mice are controlled by metabotropic glutamate receptor 5 on neurons expressing dopamine D1 receptors. Biol Psychiatry. 2013;73(3):263-70. doi:10.1016/j.biopsych.2012.07.019.

68. Lewis M, Kim SJ. The pathophysiology of restricted repetitive behavior. J Neurodev Disord. 2009;1 (2):114-32. doi:10.1007/s11689-009-9019-6.

69. Draper A, Stephenson MC, Jackson GM, Pépés S, Morgan PS, Morris $P G$, et al. Increased GABA contributes to enhanced control over motor excitability in Tourette syndrome. Curr Biol. 2014;24(19):2343-7. doi:10.1016/j.cub.2014.08.038.

70. Parr-Brownlie LC, Hyland BI. Bradykinesia induced by dopamine D2 receptor blockade is associated with reduced motor cortex activity in the rat. J Neurosci. 2005;25(24):5700-9. doi:10.1523/ JNEUROSCI.0523-05.2005.

71. Li YC, Kellendonk C, Simpson EH, Kandel ER, Gao WJ. D2 receptor overexpression in the striatum leads to a deficit in inhibitory transmission and dopamine sensitivity in mouse prefrontal cortex. Proc Natl Acad Sci USA. 2011;108(29):12107-12. doi:10.1073/pnas.1109718108.

72. Kim IH, Rossi MA, Aryal DK, Racz B, Kim N, Uezu A, et al. Spine pruning drives antipsychotic-sensitive locomotion via circuit control of striatal dopamine. Nat Neurosci. 2015;. doi:10.1038/nn.4015.

73. Morency MA, Stewart RJ, Beninger RJ. Effects of unilateral microinjections of sulpiride into the medial prefrontal cortex on circling behavior of rats. Prog Neuropsychopharmacol Biol Psychiatry. 1985;9(5-6):735-8. doi:10.1016/0278-5846(85)90051-X.

74. Aliane V, Pérez S, Nieoullon A, Deniau JM, Kemel ML. Cocaine-induced stereotypy is linked to an imbalance between the medial prefrontal and sensorimotor circuits of the basal ganglia. Eur J Neurosci. 2009;30(7):1269-79. doi:10.1111/j.1460-9568.2009.06907.x.

75. Anderson SW, Bechara A, Damasio H, Tranel D, Damasio AR. Impairment of social and moral behavior related to early damage in human prefrontal cortex. Nat Neurosci. 1999;2(11):1032-7. doi:10.1038/14833.

76. Tsunada J, Sawaguchi T. Neuronal categorization and discrimination of social behaviors in primate prefrontal cortex. PLoS One. 2012; doi:10.1371/journal.pone.0052610.

77. Yizhar O, Fenno LE, Prigge M, Schneider F, Davidson TJ, Ogshea DJ, et al. Neocortical excitation/inhibition balance in information processing and social dysfunction. Nature. 2011;477(7363):171-8. doi:10.1038/ nature10360.

78. Testa-Silva G, Loebel A, Giugliano M, De Kock CPJ, Mansvelder HD Meredith RM. Hyperconnectivity and slow synapses during early development of medial prefrontal cortex in a mouse model for mental retardation and Autism. Cereb Cortex. 2012;22(6):1333-42. doi:10.1093/ cercor/bhr224.
79. Hines RM, Wu L, Hines DJ, Steenland H, Mansour S, Dahlhaus R, et al. Synaptic imbalance, stereotypies, and impaired social interactions in mice with altered neuroligin 2 expression. J Neurosci. 2008;28(24):605567. doi:10.1523/JNEUROSCI.0032-08.2008.

80. Kalivas PW, Duffy P. Repeated cocaine administration alters extracellular glutamate in the ventral tegmental area. J Neurochem. 1998;70(4):1497-502.

81. Takahata R, Moghaddam B. Activation of glutamate neurotransmission in the prefrontal cortex sustains the motoric and dopaminergic effects of phencyclidine. Neuropsychopharmacology. 2003;28(6):1117-24.

82. Gunaydin LA, Grosenick L, Finkelstein JC, Kauvar IV, Fenno LE, Adhikari A, et al. Natural neural projection dynamics underlying social behavior. Cell. 2014;157(7):1535-51. doi:10.1016/j.cell.2014.05.017.

83. Guariglia SR, Chadman KK. Water T-maze: a useful assay for determination of repetitive behaviors in mice. J Neurosci Methods. 2013;220(1):24-9. doi:10.1016/j.jneumeth.2013.08.019.

84. Scattoni ML, Martire A, Cartocci G, Ferrante A, Ricceri L. Reduced social interaction, behavioural flexibility and BDNF signalling in the BTBR $\mathrm{T}+\mathrm{tf} / \mathrm{J}$ strain, a mouse model of autism. Behav Brain Res. 2013;251:3540. doi:10.1016/j.bbr.2012.12.028.

85. Burket JA, Benson AD, Tang AH, Deutsch SI. D-Cycloserine improves sociability in the BTBR T + Itpr3tf/J mouse model of autism spectrum disorders with altered Ras/Raf/ERK1/2 signaling. Brain Res Bull. 2013;96:62-70. doi:10.1016/j.brainresbull.2013.05.003.

86. Etherton MR, Blaiss CA, Powell CM, Südhof TC. Mouse neurexin-1a deletion causes correlated electrophysiological and behavioral changes consistent with cognitive impairments. Proc Natl Acad Sci USA. 2009;106(42):17998-8003. doi:10.1073/pnas.0910297106.

87. Grayton HM, Missler M, Collier DA, Fernandes C. Altered social behaviours in neurexin 1 a knockout mice resemble core symptoms in neurodevelopmental disorders. PLoS One. 2013;8(6):67.

88. Rabaneda LG, Robles-Lanuza E, Nieto-González J, Scholl FG. Neurexin dysfunction in adult neurons results in autistic-like behavior in mice. Cell Reports. 2014;8(2):338-46. doi:10.1016/j.celrep.2014.06.022.

89. Cheh MA, Millonig JH, Roselli LM, Ming X, Jacobsen E, Kamdar $S$, et al. En2 knockout mice display neurobehavioral and neurochemical alterations relevant to autism spectrum disorder. Brain Res. 2006;1116(1):166-76.

90. Sgadò P, Genovesi S, Kalinovsky A, Zunino G, Macchi F, Allegra M, et al. Loss of GABAergic neurons in the hippocampus and cerebral cortex of engrailed-2 null mutant mice: implications for autism spectrum disorders. Exp Neurol. 2013;247:496-505. doi:10.1016/j. expneurol.2013.01.021.

91. Wurzman R, Forcelli PA, Griffey CJ, Kromer LF. Repetitive grooming and sensorimotor abnormalities in an ephrin-A knockout model for autism spectrum disorders. Behav Brain Res. 2015;278:115-28.

92. Gerlai R. Eph receptors and neural plasticity. Nat Rev Neurosci. 2001;2(3):205-9.

93. Bolz J, Uziel D, Mühlfriedel S, Güllmar A, Peuckert C, Zarbalis K, et al. Multiple roles of ephrins during the formation of thalamocortical projections: maps and more. J Neurobiol. 2004;59(1):82-94.

94. Hung AY, Futai K, Sala C, Valtschanoff JG, Ryu J, Woodworth MA, et al. Smaller dendritic spines, weaker synaptic transmission, but enhanced spatial learning in mice lacking Shank1. J Neurosci. 2008;28(7):1697-708.

95. Gkogkas CG, Khoutorsky A, Ran I, Rampakakis E, Nevarko T, Weatherill $\mathrm{DB}$, et al. Autism-related deficits via dysregulated elF4E-dependent translational control. Nature. 2013;493(7432):371-7.

96. Chao HT, Chen H, Samaco RC, Xue M, Chahrour M, Yoo J, et al. Dysfunction in GABA signalling mediates autism-like stereotypies and Rett syndrome phenotypes. Nature. 2010;468(7321):263-9.

97. DeLorey TM, Sahbaie P, Hashemi E, Homanics GE, Clark JD. Gabrb3 gene deficient mice exhibit impaired social and exploratory behaviors, deficits in non-selective attention and hypoplasia of cerebellar vermal lobules: a potential model of autism spectrum disorder. Behav Brain Res. 2008;187(2):207-20.

98. Dansie LE, Phommahaxay K, Okusanya AG, Uwadia J, Huang M, Rotschafer SE, et al. Long-lasting effects of minocycline on behavior in young but not adult Fragile X mice. Neuroscience. 2013;246:186-98. doi:10.1016/j.neuroscience.2013.04.058. 
99. Bakker CE, Verheij C, Willemsen R, Van Der Helm R, Oerlemans F, Vermey $\mathrm{M}$, et al. Fmr1 knockout mice: a model to study fragile $\mathrm{X}$ mental retardation. Cell. 1994;78(1):23-33.

100. Gibson JR, Bartley AF, Hays SA, Huber KM. Imbalance of neocortical excitation and inhibition and altered UP states reflect network hyperexcitability in the mouse model of fragile $X$ syndrome. J Neurophysiol. 2008;100(5):2615-26.

101. Wang X, McCoy PA, Rodriguiz RM, Pan Y, Je HS, Roberts AC, et al. Synaptic dysfunction and abnormal behaviors in mice lacking major isoforms of Shank3. Hum Mol Genet. 2011;20(15):3093-108. doi:10.1093/hmg/ ddr212.
102. Shahbazian MD, Young Jl, Yuva-Paylor LA, Spencer CM, Antalffy BA, Noebels JL, et al. Mice with truncated MeCP2 recapitulate many Rett syndrome features and display hyperacetylation of histone H3. Neuron. 2002:35(2):243-54

103. Veenstra-VanderWeele J, Muller CL, Iwamoto H, Sauer JE, Owens WA, Shah $C R$, et al. Autism gene variant causes hyperserotonemia, serotonin receptor hypersensitivity, social impairment and repetitive behavior. Proc Natl Acad Sci USA. 2012;109(14):5469-74. 